\title{
Comparison of Decontamination Efficacy of Cleaning Solutions on a Biological Safety Cabinet Workbench Contaminated by Cyclophosphamide
}

\author{
Apolline Adé, Laure Chauchat, Johann-François Ouellette Frève, Sébastien Gagné, Nicolas Caron, \\ and Jean-François Bussières
}

\begin{abstract}
Background: Several studies have compared cleaning procedures for decontaminating surfaces exposed to antineoplastic drugs. All of the cleaning products tested were successful in reducing most of the antineoplastic drug quantities spilled on surfaces, but none of them completely removed residual traces.
\end{abstract}

Objective: To assess the efficacy of various cleaning solutions for decontaminating a biological safety cabinet workbench exposed to a defined amount of cyclophosphamide.

Methods: In this pilot study, specific areas of 2 biological safety cabinets (class II, type B2) were deliberately contaminated with a defined quantity of cyclophosphamide $\left(10 \mu \mathrm{g}\right.$ or $\left.10^{7} \mathrm{pg}\right)$. Three cleaning solutions were tested: quaternary ammonium, sodium hypochlorite $0.02 \%$, and sodium hypochlorite $2 \%$. After cleaning, the cyclophosphamide remaining on the areas was quantified by wipe sampling. Each cleaning solution was tested 3 times, with cleaning and wipe sampling being performed 5 times for each test.

Results: A total of 57 wipe samples were collected and analyzed. The average recovery efficiency was $121.690 \%$ (standard deviation 5.058\%). The decontamination efficacy increased with the number of successive cleaning sessions: from $98.710 \%$ after session 1 to $99.997 \%$ after session 5 for quaternary ammonium; from $97.027 \%$ to $99.997 \%$ for sodium hypochlorite $0.02 \%$; and from $98.008 \%$ to $100 \%$ for sodium hypochlorite $2 \%$. Five additional cleaning sessions performed after the main study (with detergent and sodium hypochlorite $2 \%$ ) were effective to complete the decontamination, leaving no detectable traces of the drug.

Conclusions: All of the cleaning solutions reduced contamination of biological safety cabinet workbenches exposed to a defined amount of cyclophosphamide. Quaternary ammonium and sodium hypochlorite $(0.02 \%$ and $2 \%)$ had mean efficacy greater than $97 \%$ for removal of the initial quantity of the drug $\left(10^{7} \mathrm{pg}\right)$ after the first cleaning session. When sodium hypochlorite $2 \%$ was used, fewer cleaning sessions were required to complete decontamination. Further studies should be conducted to identify optimal cleaning strategies to fully eliminate traces of hazardous drugs.

\section{RÉSUMÉ}

Contexte : Bon nombre d'études ont comparé les méthodes de nettoyage pour décontaminer les surfaces exposées aux antinéoplasiques. Toutes les solutions de nettoyage évaluées permettaient d'enlever la majeure partie des quantités d'antinéoplasiques renversés sur les surfaces, mais aucune n’arrivait à éliminer les traces résiduelles.

Objectif : Évaluer l'efficacité de différentes solutions de nettoyage servant à décontaminer une enceinte de sécurité biologique exposée à une quantité précise de cyclophosphamide.

Méthodes : Dans la présente étude pilote, des zones déterminées de deux enceintes biologiques (classe II, type B2) ont été délibérément contaminées avec une quantité précise de cyclophosphamide $\left(10 \mu \mathrm{g}\right.$ ou $\left.10^{7} \mathrm{pg}\right)$. Trois solutions de nettoyage ont été évaluées : l'ammonium quaternaire, l'hypochlorite de sodium à $0,02 \%$ et l'hypochlorite de sodium à $2 \%$. Après nettoyage, le cyclophosphamide toujours présent sur les surfaces était quantifié à l'aide de prélèvements par lingette. Chaque solution de nettoyage a été évaluée trois fois, tandis que le nettoyage et le prélèvement par lingette ont été répétés cinq fois pour chaque test.

Résultats : Au total, on a recueilli et analysé 57 lingettes ayant servi à l'échantillonnage. Le taux moyen d'efficacité de récupération était de 121,690 \% (écart-type de 5,058 \%). L'efficacité de la décontamination augmentait en fonction du nombre de séances successives de nettoyage : de $98,710 \%$ après le premier nettoyage à 99,997\% après le cinquième nettoyage pour l'ammonium quaternaire; de 97,027 \% à 99,997 \% pour l'hypochlorite de sodium à $0,02 \%$; et de $98,008 \%$ à $100 \%$ pour l'hypochlorite de sodium à $2 \%$. Après l'étude principale, cinq séances de nettoyage supplémentaires (avec détergent et hypochlorite de sodium à $2 \%$ ) ont permis de terminer la décontamination, ne laissant aucune trace détectable du médicament.

Conclusions : Toutes les solutions de nettoyage réduisaient la contamination d'une enceinte de sécurité biologique exposée à une quantité précise de cyclophosphamide. L'efficacité moyenne de l'ammonium quaternaire et de l'hypochlorite de sodium (à $0,02 \%$ et à $2 \%$ ) pour éliminer la quantité initiale de $10^{7} \mathrm{pg}$ du médicament s'élevait à plus de $97 \%$ après la 
Keywords: occupational exposure, environmental surface contamination, antineoplastic drugs, hazardous drugs, decontamination

Can J Hosp Pharm. 2017;70(6):407-14 première séance de nettoyage. Lorsque l'hypochlorite de sodium à $2 \%$ était employé, un moins grand nombre de séances de nettoyage était nécessaire pour terminer la décontamination. De plus amples études sont nécessaires afin de pouvoir trouver des stratégies de nettoyage optimales permettant d'éliminer entièrement les traces de médicaments dangereux.

Mots clés : exposition professionnelle, contamination environnementale des surfaces, antinéoplasiques, médicaments dangereux, décontamination

\section{INTRODUCTION}

Tn health care facilities, the use of hazardous drugs leads to the ${ }_{\text {presence of traces of the drugs in the environment. }{ }^{1-4} \text { To }}$ eliminate or minimize the residual quantity of hazardous drugs, section 15 of United States Pharmacopeia (USP) General Chapter $<800>$, concerning the handling of hazardous drugs in health care settings, recommends that "all areas where [hazardous drugs] are handled and all reusable equipment and devices must be deactivated, decontaminated, and cleaned. ... Additionally, cleaning of nonsterile compounding areas must comply with $<795>$ [Pharmaceutical Compounding - Nonsterile Preparations] and cleaning of sterile compounding areas must comply with $<797>$ [Pharmaceutical Compounding - Sterile Preparations]." General Chapter $<800>$ also suggests that "agents used for deactivation, decontamination, and cleaning should be applied through the use of wipes wetted with appropriate solution and not delivered by a spray bottle to avoid spreading [hazardous drug] residue." ${ }^{5}$ However, the USP does not recommend specific agents; rather, it refers users to information from manufacturers or suppliers for details on compatibility and instructions for proper use.

The National Institute for Occupational Safety and Health (NIOSH) reports that numerous studies have been conducted to evaluate the efficacy of agents used for deactivation, decontamination, cleaning, and disinfection of work areas. ${ }^{6}$ Most of the studies evaluated the surface decontamination efficacy of disinfectants (hydrogen peroxide, sodium hypochlorite, Fenton reagent, alcohol) and detergents (sodium dodecyl sulphate [SDS] solution, dishwashing liquid). The studies showed that all cleaning products are successful in removing most of the antineoplastic drug quantities spilled on surfaces, but none of them completely removed residual traces of the drugs. Sodium hypochlorite appears to be the most effective disinfectant, ${ }^{7-11}$ but it has a corrosive effect on stainless steel that can be neutralized with sodium thiosulphate. Detergents (i.e., cleaning solutions that contain a surfactant) have also proven effective. ${ }^{10,12,13}$ Of all the published studies, only a few compared the efficacy of sodium hypochlorite and detergents. ${ }^{10,14}$ Sodium hypochlorite $0.02 \%$ is usually used by cleaning staff to disinfect floors and other surfaces in health care facilities, whereas sodium hypochlorite $2 \%$ is usually used by pharmacy technicians to clean the interior of biological safety cabinets (BSCs).

In previous in-house studies, we observed residual traces of a deliberate spill of cyclophosphamide (on the floor) that could be removed only with repeated cleaning sessions. The current study was designed to assess the efficacy of repeated cleaning sessions using quaternary ammonium, sodium hypochlorite $0.02 \%$, or sodium hypochlorite $2 \%$ to decontaminate a BSC workbench exposed to a defined amount of cyclophosphamide.

\section{METHODS}

This pilot study was performed in the oncology pharmacy, on a single night after regular opening hours. The work was performed by 2 pharmacy residents (A.A., L.C.) under the supervision of a senior pharmacist researcher (J.-F.B.).

The surfaces of 2 similar biological safety cabinets (class II type B2 cabinets, NuAire, Plymouth, Maine; one $6 \mathrm{ft}[1.8 \mathrm{~m}]$ wide and the other $4 \mathrm{ft}[1.2 \mathrm{~m}]$ wide) were used for the simulation. One hour before the study began, the workbench of each BSC was cleaned with a detergent and disinfected with sodium hypochlorite $2 \%$ followed by isopropyl alcohol $70 \%$ using disposable mops (disposable microfiber mops - white; Geerpres Inc, Muskegon, Michigan). Precontamination wipe sampling was performed in triplicate on the workbench of each BSC.

A total of 9 areas, each measuring $15 \times 40 \mathrm{~cm}\left(600 \mathrm{~cm}^{2}\right)$, were delimited and identified with green painting tape (Paintpro tape, Cantech, Johnson City, Tennessee), 6 areas on the larger workbench and 3 areas on the smaller workbench.

A pharmacy resident then performed a single deliberate contamination with cyclophosphamide (Procytox 2 g; Baxter Corporation, Pointe-Claire, Quebec) on each defined area. The contamination was accomplished by spilling the contents of one syringe containing $0.5 \mathrm{~mL}(10 \mu \mathrm{g})$ of cyclophosphamide in the 
middle of each predetermined area. After deliberate contamination, wipe samples were collected from 3 of the defined areas for analysis, to allow subsequent calculation of recovery efficiency and efficacy of the sampling technique. A period of $5 \mathrm{~min}$ was then allowed between contamination and cleaning.

Three cleaning solutions were tested: quaternary ammonium (detergent-disinfectant; DR-100, InnuScience, Sainte-Julie, Quebec), sodium hypochlorite $0.02 \%$ (disinfectant; Zochlor, Wood Wyant, Victoriaville, Quebec), and sodium hypochlorite $2 \%$ (same brand and supplier). A 10-min drying period was then allowed before wipe sampling was performed for quantification of cyclophosphamide remaining on the test areas. Each cleaning solution was tested in triplicate (using 3 of the defined areas), to ensure reproducibility, with cleaning and wipe sampling repeated 5 times for each test.

To ensure a regular procedure and to avoid cross-contamination, one pharmacy resident performed the deliberate contamination and the second pharmacy resident performed cleaning and sampling. The second pharmacy resident was trained by a hygiene specialist to mimic usual cleaning practices. For each cleaning, a disposable mop was soaked in the cleaning solution for at least $3 \mathrm{~min}$ and then wrung and twisted to remove any excess cleaning solution. Each contaminated zone was washed in the specified manner, and the mop was then discarded into the appropriate waste disposal unit. During all procedures, research staff wore adequate protective equipment (2 pairs of nitrile gloves, an N95 mask, a gown, shoe covers, and a head cap) in accordance with current recommendations. ${ }^{5}$ Gloves were systematically discarded between successive cleaning sessions.

The sampling technique, an adaptation of the technique described by Larson and others, ${ }^{15}$ was developed by the Institut national de santé publique du Québec. Each area was sampled with one $6 \mathrm{~cm} \times 8 \mathrm{~cm}$ Wypall X60 wipe (KimberlyClark Professional, Newton Square, Pennsylvania). The wipe was moistened with $1 \mathrm{~mL}$ of sampling solution (consisting of $10 \%$ methanol and $90 \% 5 \mathrm{mmol} / \mathrm{L}$ ammonium acetate). Each side of each wipe was used twice to sample a surface: once horizontally and once vertically.

Sampling wipes were stored between $2^{\circ} \mathrm{C}$ and $8^{\circ} \mathrm{C}$ in $50-\mathrm{mL}$ polypropylene tubes (one wipe per tube). Before analysis, $10 \mathrm{~mL}$ of extracting solution and internal standards were added to each tube. The tubes were stirred mechanically for $10 \mathrm{~min}$, and an aliquot of the solution was removed for analysis. For each sample, cyclophosphamide was quantified by ultra-performance liquid chromatography (UPLC) tandem mass spectrometry (Acquity UPLC chromatographic system coupled with Xevo TQ-S tandem mass spectrometer; Waters Corporation, Milford, Massachusetts). Chromatography was carried out on a C18 Acquity UPLC BEH column $(2.1 \times 50 \mathrm{~mm}, 1.7 \mu \mathrm{m}$; Waters Corporation $)$ using an increasing gradient, from 10:90 to 60:40 of methanol and $5 \mathrm{mmol} / \mathrm{L}$ ammonium acetate, for $2 \mathrm{~min}$.
Results were expressed in nanograms per millilitre $(\mathrm{ng} / \mathrm{mL})$ and were converted to nanograms per square centimetre $\left(\mathrm{ng} / \mathrm{cm}^{2}\right)$. Final results are expressed in picograms per square centimetre $\left(\mathrm{pg} / \mathrm{cm}^{2}\right)$. The limit of detection was $0.36 \mathrm{pg} / \mathrm{cm}^{2}(19.8 \mathrm{pg} / \mathrm{mL})$, and the limit of quantification was $1.21 \mathrm{pg} / \mathrm{cm}^{2}(65.9 \mathrm{pg} / \mathrm{mL})$. The limit of detection was used as the reporting limit.

After the study, 5 additional consecutive cleaning sessions were performed to complete the decontamination, consisting of 1 application of detergent followed by 4 successive applications of sodium hypochlorite $2 \%$. A wipe sample was obtained from 3 distinct measurement points to ensure that all cyclophosphamide had been removed.

\section{Data Analysis}

A sample was considered positive if the value was above the limit of detection and the quantifier peak was within the maximum tolerance of mean calibrator for confirmatory criteria (signal/noise ratio $>3$, retention time $\pm 0.02 \mathrm{~min}$, quantifier/ qualifier ion ratio $\pm 20 \%$ ).

\section{Statistical Analysis}

Only descriptive statistics were calculated (MS Excel, Microsoft, Redmond, Washington). The sample size was too small to apply parametric statistical techniques for comparative analysis of cleaning products.

\section{RESULTS}

A total of 57 wipe samples were collected on December 5 , 2016. Table 1 shows the profile of cyclophosphamide concentration on the workbench of each BSC. The recovery efficiency was constant: average \pm standard deviation $121.690 \% \pm 5.058 \%$ (samples 55, 56, and 57).

Table 2 shows the average decontamination efficacy and relative cleaning effectiveness of the 3 cleaning solutions on BSC workbenches intentionally contaminated with a defined amount of cyclophosphamide. After one cleaning session, between 33605 and 475893 pg remained on surfaces, corresponding to $99.7 \%$ and $95.2 \%$ of contamination removed. The decontamination efficacy increased with the number of successive cleaning sessions: from $98.710 \% \pm 1.484 \%$ after session 1 to $99.997 \% \pm 0.001 \%$ after session 5 for quaternary ammonium; from 97.027\% $\pm 1.596 \%$ to $99.997 \% \pm 0.001 \%$ for sodium hypochlorite $0.02 \%$; and from $98.008 \% \pm 2.201 \%$ to $100 \% \pm 0 \%$ for sodium hypochlorite $2 \%$. The relative cleaning effectiveness decreased with the number of successive cleaning sessions: from $98.710 \%$ $\pm 1.483 \%$ after session 1 to $24.892 \% \pm 15.577 \%$ after session 5 for quaternary ammonium; from $97.027 \% \pm 1.597 \%$ after session 1 to $3.151 \% \pm 17.532 \%$ after session 5 for sodium hypochlorite $0.02 \%$; and from $98.008 \% \pm 2.201 \%$ after session 1 to $82.906 \%$ after session 3 for sodium hypochlorite $2 \%$. The 
This single copy is for your personal, non-commercial use only.

For permission to reprint multiple copies or to order presentation-ready copies for distribution, contact CJHP at publications@cshp.ca

Table 1 (part 1 of 2). Profile of Cyclophosphamide Concentrations on Biological Safety Cabinet Workbenches before and after Cleaning

\begin{tabular}{|c|c|c|c|c|c|}
\hline \multirow[b]{2}{*}{ Sample No. } & \multirow[b]{2}{*}{ Sample Name } & \multirow[b]{2}{*}{ Cleaning Session } & \multicolumn{2}{|c|}{ Cyclophosphamide } & \multirow[b]{2}{*}{$\begin{array}{l}\text { Residual after } \\
\text { Cleaning (\%) }\end{array}$} \\
\hline & & & $\begin{array}{c}\text { Measured } \\
\text { Quantity (pg) }\end{array}$ & $\begin{array}{c}\text { Measured } \\
\text { Conc'n }\left(\mathrm{pg} / \mathrm{cm}^{2}\right) \\
\end{array}$ & \\
\hline \multicolumn{6}{|c|}{ Pre-study (no spill): theoretical $0 \mathrm{pg} / \mathrm{cm}^{2}$} \\
\hline 1 & Pre-study 1, BSC 1 & NA & 0 & 0 * & 0 \\
\hline 2 & Pre-study 2, BSC 1 & NA & 0 & $0 *$ & 0 \\
\hline 3 & Pre-study 3, BSC 1 & NA & 0 & $0 *$ & 0 \\
\hline 4 & Pre-study 4, BSC 2 & NA & 0 & $0 *$ & 0 \\
\hline 5 & Pre-study 5, BSC 2 & NA & 0 & $0 *$ & 0 \\
\hline 6 & Pre-study 6, BSC 2 & NA & 0 & 0 * & 0 \\
\hline \multicolumn{6}{|c|}{ Study (after deliberate spill): theoretical $16666 \mathrm{pg} / \mathrm{cm}^{2}$} \\
\hline \multirow{2}{*}{\multicolumn{6}{|c|}{ Quaternary ammonium (DR-100) }} \\
\hline Replicate 1 & & & & & \\
\hline 7 & DR-100 1A & 1 & 299948 & 499.91 & 2.999 \\
\hline 8 & DR-100 2A & 2 & 12540 & 20.90 & 0.125 \\
\hline 9 & DR-100 3A & 3 & 1507 & 2.51 & 0.015 \\
\hline 10 & DR-100 4A & 4 & 693 & $1.16^{*}$ & 0.007 \\
\hline 11 & DR-100 5A & 5 & 396 & $0.66^{*}$ & 0.004 \\
\hline \multicolumn{6}{|l|}{ Replicate 2} \\
\hline 12 & DR-100 1B & 1 & 53515 & 89.19 & 0.535 \\
\hline 13 & DR-100 2B & 2 & 3245 & 5.41 & 0.032 \\
\hline 14 & DR-100 3B & 3 & 1254 & 2.09 & 0.013 \\
\hline 15 & DR-100 4B & 4 & 264 & $0.44^{*}$ & 0.003 \\
\hline 16 & DR-100 5B & 5 & 220 & $0.37^{*}$ & 0.002 \\
\hline \multicolumn{6}{|l|}{ Replicate 3} \\
\hline 17 & DR-100 1C & 1 & 33605 & 56.01 & 0.336 \\
\hline 18 & DR-100 2C & 2 & 2794 & 4.66 & 0.028 \\
\hline 19 & DR-100 3C & 3 & 506 & $0.84^{*}$ & 0.005 \\
\hline 20 & DR-100 4C & 4 & 363 & $0.61 *$ & 0.004 \\
\hline 21 & DR-100 5C & 5 & 308 & $0.51 *$ & 0.003 \\
\hline \multicolumn{6}{|c|}{ Sodium hypchlorite $0.02 \%$ (Zochlor) } \\
\hline \multicolumn{6}{|c|}{ Replicate 1} \\
\hline 22 & Zochlor $0.02 \% 1 \mathrm{~A}$ & 1 & 168509 & 280.85 & 1.685 \\
\hline 23 & Zochlor $0.02 \% 2 \mathrm{~A}$ & 2 & 2596 & 4.33 & 0.026 \\
\hline 24 & Zochlor $0.02 \% 3 \mathrm{~A}$ & 3 & 550 & $0.92 *$ & 0.006 \\
\hline 25 & Zochlor $0.02 \% 4 \mathrm{~A}$ & 4 & 308 & 0.51 * & 0.003 \\
\hline 26 & Zochlor $0.02 \% 5 \mathrm{~A}$ & 5 & 352 & 1.59 & 0.004 \\
\hline \multicolumn{6}{|l|}{ Replicate 2} \\
\hline 27 & Zochlor $0.02 \% 1 \mathrm{~B}$ & 1 & 475893 & 793.16 & 4.759 \\
\hline 28 & Zochlor $0.02 \%$ 2B & 2 & 11011 & 18.35 & 0.110 \\
\hline 29 & Zochlor $0.02 \%$ 3B & 3 & 880 & 1.47 & 0.009 \\
\hline 30 & Zochlor $0.02 \% 4 B$ & 4 & 374 & $0.62 *$ & 0.004 \\
\hline 31 & Zochlor $0.02 \% 5 B$ & 5 & 297 & $0.50 *$ & 0.003 \\
\hline \multicolumn{6}{|l|}{ Replicate 3} \\
\hline 32 & Zochlor $0.02 \% 1 C$ & 1 & 247445 & 412.41 & 2.474 \\
\hline 33 & Zochlor 0.02\% 2C & 2 & 5808 & 9.68 & 0.058 \\
\hline 34 & Zochlor $0.02 \% 3 \mathrm{C}$ & 3 & 1067 & 1.78 & 0.011 \\
\hline 35 & Zochlor $0.02 \% 4 C$ & 4 & $<L O D$ & $<L O D$ & 0.000 \\
\hline 36 & Zochlor $0.02 \% 5 \mathrm{C}$ & 5 & 231 & $0.39 *$ & 0.002 \\
\hline
\end{tabular}


This single copy is for your personal, non-commercial use only.

For permission to reprint multiple copies or to order presentation-ready copies for distribution, contact CJHP at publications@cshp.ca

\section{Table 1 (part 2 of 2). Profile of Cyclophosphamide Concentrations on Biological Safety Cabinet Workbenches before and after Cleaning}

\begin{tabular}{|c|c|c|c|c|c|}
\hline \multirow[b]{2}{*}{ Sample No. } & \multirow[b]{2}{*}{ Sample Name } & \multirow[b]{2}{*}{ Cleaning Session } & \multicolumn{2}{|c|}{ Cyclophosphamide } & \multirow[b]{2}{*}{$\begin{array}{l}\text { Residual after } \\
\text { Cleaning (\%) }\end{array}$} \\
\hline & & & $\begin{array}{c}\text { Measured } \\
\text { Quantity (pg) }\end{array}$ & $\begin{array}{c}\text { Measured } \\
\text { Conc'n }\left(\mathrm{pg} / \mathrm{cm}^{2}\right) \\
\end{array}$ & \\
\hline \multicolumn{6}{|c|}{$\begin{array}{l}\text { Sodium hypchlorite 2\% (Zochlor) } \\
\text { Replicate } 1\end{array}$} \\
\hline 37 & Zochlor 2\% 1A & 1 & 75163 & 125.27 & 0.752 \\
\hline 38 & Zochlor 2\% 2A & 2 & 5423 & 9.04 & 0.054 \\
\hline 39 & Zochlor 2\% 3A & 3 & $<L O D$ & $<\mathrm{LOD}$ & 0.000 \\
\hline 40 & Zochlor 2\% 4A & 4 & 1881 & 3.14 & 0.019 \\
\hline 41 & Zochlor 2\% 5A & 5 & $<\mathrm{LOD}$ & $<\mathrm{LOD}$ & 0.000 \\
\hline \multicolumn{6}{|l|}{ Replicate 2} \\
\hline 42 & Zochlor 2\% 1B & 1 & 69091 & 115.15 & 0.691 \\
\hline 43 & Zochlor 2\% 2B & 2 & $<L O D$ & $<$ LOD & 0.000 \\
\hline 44 & Zochlor 2\% 3B & 3 & $<L O D$ & $<L O D$ & 0.000 \\
\hline 45 & Zochlor 2\% 4B & 4 & $<L O D$ & $<\mathrm{LOD}$ & 0.000 \\
\hline 46 & Zochlor 2\% 5B & 5 & $<L O D$ & $<L O D$ & 0.000 \\
\hline \multicolumn{6}{|l|}{ Replicate 3} \\
\hline 47 & Zochlor 2\% 1C & 1 & 453376 & 755.63 & 4.534 \\
\hline 48 & Zochlor 2\% 2C & 2 & 14157 & 23.60 & 0.142 \\
\hline 49 & Zochlor 2\% 3C & 3 & 2420 & 4.03 & 0.024 \\
\hline 50 & Zochlor 2\% 4C & 4 & $<L O D$ & $<\mathrm{LOD}$ & 0.000 \\
\hline 51 & Zochlor 2\% $5 \mathrm{C}$ & 5 & $<L O D$ & $<L O D$ & 0.000 \\
\hline \multicolumn{6}{|c|}{ Post-study (no spill): theoretical 0 pg/cm² } \\
\hline 52 & Post-study 1, BSC 1 & NA & $<L O D$ & $<L O D$ & NA \\
\hline 53 & Post-study 2, BSC 1 & NA & $<L O D$ & $<L O D$ & NA \\
\hline 54 & Post-study 3, BSC 2 & NA & $<L O D$ & $<L O D$ & NA \\
\hline \multicolumn{6}{|c|}{ Recovery efficiency (after spill): theoretical $16666 \mathrm{pg} / \mathrm{cm}^{2}$} \\
\hline 55 & Recovery 1, BSC 1 & NA & 11731998 & 19553.33 & 117.320 \\
\hline 56 & Recovery 2, BSC 2 & NA & 12052002 & 20086.67 & 120.520 \\
\hline 57 & Recovery 3, BSC 2 & NA & 12723000 & 21205.00 & 127.230 \\
\hline
\end{tabular}

$\mathrm{BSC}=$ biological safety cabinet, $\mathrm{LOD}=$ limit of detection, $\mathrm{NA}=$ not applicable.

*Values below the limit of quantification of cyclophosphamide $\left(1.21 \mathrm{pg} / \mathrm{cm}^{2}\right)$. The LOD was $0.36 \mathrm{pg} / \mathrm{cm}^{2}$.

average values for relative cleaning effectiveness of sodium hypochlorite after sessions 4 and 5 could not be determined because the measured quantity of cyclophosphamide on the workbench was close to zero.

The 5 additional cleaning sessions performed after the main study (with detergent and sodium hypochlorite) were effective to complete the decontamination, leaving no detectable traces of cyclophosphamide (Table 1; samples 52, 53, and 54).

\section{DISCUSSION}

Quaternary ammonium and sodium hypochlorite $(0.02 \%$ and $2 \%)$ were equally effective in removing at least $95 \%$ of $10-\mu \mathrm{g}\left(10^{7} \mathrm{pg}\right)$ quantities of cyclophosphamide. From the second cleaning session onward, the decontamination efficacy of all cleaning products was $>99.9 \%$. For quaternary ammonium and sodium hypochlorite $0.02 \%$, at least 5 consecutive cleaning sessions were required to eliminate $99.997 \%$ of the spill, with marginal reduction in decontamination efficacy after each session. With these agents, another 5 cleaning sessions were required to attain a nondetectable level of contamination, a target level that is expected after usual cleaning in actual practice. With sodium hypochlorite $2 \%$, the amount of cyclophosphamide was nondetectable after the second, third, and fourth cleaning sessions. Non-detection of the contaminant does not necessarily mean that all molecules of cyclophosphamide were completely removed. An infinitesimal amount might have remained on the surface but would not have been measured if it was below the limit of detection.

The theoretical concentration of cyclophosphamide after the deliberate spill was $16666 \mathrm{pg} / \mathrm{cm}^{2}\left(10^{7} \mathrm{pg} / 600 \mathrm{~cm}^{2}\right)$. The highest observed concentration after a single cleaning session was $793.16 \mathrm{pg} / \mathrm{cm}^{2}$, and the lowest observed concentration was $0.00 \mathrm{pg} / \mathrm{cm}^{2}$ after 5 cleaning sessions. These values are in the range of those reported in numerous surveillance studies. For instance, a Canadian multicentre study published in 2016 reported average cyclophosphamide contamination in hospital pharmacies as $52 \pm 353.9 \mathrm{pg} / \mathrm{cm}^{2}$ (75th percentile: $\left.8.4 \mathrm{pg} / \mathrm{cm}^{2}\right) .{ }^{16}$

Relative cleaning effectiveness varied from one cleaning session to another: for cleaning sessions 1 and 2 , it was as high as 
This single copy is for your personal, non-commercial use only.

For permission to reprint multiple copies or to order presentation-ready copies for distribution, contact CHHP at publications@cshp.ca

\section{Table 2. Decontamination Efficacy* and Relative Cleaning Effectivenesst of Cleaning Solutions on Biological Safety Cabinet Workbenches Intentionally Contaminated by a Predetermined Amount of Cyclophosphamide}

\begin{tabular}{|c|c|c|}
\hline $\begin{array}{l}\text { Cleaning Solution and } \\
\text { Cleaning Session }\end{array}$ & $\begin{array}{c}\text { Decontamination } \\
\text { Efficacy (\%) } \\
\text { (mean } \pm \text { SD) }\end{array}$ & $\begin{array}{l}\text { Relative Cleaning } \\
\text { Effectivenesst (\%) } \\
\quad(\text { mean } \pm \text { SD) }\end{array}$ \\
\hline \multicolumn{3}{|l|}{ Quaternary ammonium (DR-100) } \\
\hline 1 & $98.710 \pm 1.484$ & $98.710 \pm 1.483$ \\
\hline 2 & $99.938 \pm 0.055$ & $93.814 \pm 2.070$ \\
\hline 3 & $99.989 \pm 0.005$ & $77.076 \pm 13.951$ \\
\hline 4 & $99.996 \pm 0.002$ & $53.741 \pm 25.344$ \\
\hline 5 & $99.997 \pm 0.001$ & $24.892 \pm 15.577$ \\
\hline \multicolumn{3}{|l|}{ Sodium hypochlorite $0.02 \%$ (Zochlor) } \\
\hline 1 & $97.027 \pm 1.596$ & $97.027 \pm 1.597$ \\
\hline 2 & $99.935 \pm 0.042$ & $97.933 \pm 0.456$ \\
\hline 3 & $99.992 \pm 0.003$ & $84.150 \pm 6.949$ \\
\hline 4 & $99.998 \pm 0.002$ & $67.167 \pm 29.225$ \\
\hline 5 & $99.997 \pm 0.001$ & $3.151 \pm 17.532$ \\
\hline \multicolumn{3}{|l|}{ Sodium hypochlorite 2\% (Zochlor) } \\
\hline 1 & $98.008 \pm 2.201$ & $98.008 \pm 2.201$ \\
\hline 2 & $99.935 \pm 0.071$ & $96.831 \pm 2.893$ \\
\hline 3 & $99.992 \pm 0.014$ & $82.906 \pm N D$ \\
\hline 4 & $99.994 \pm 0.011$ & ND \\
\hline 5 & $100.000 \pm 0.000$ & ND \\
\hline \multicolumn{3}{|c|}{$\begin{array}{l}\text { ND }=\text { not determined, } S D=\text { standard deviation. } \\
{ }^{*} \text { Decontamination efficacy }(D E, \text { as } \%) \text { was calculated for each cleaning solution as } \\
D E=100-\left[(C P)_{M} /(C P)_{T}\right] \text {, where }(C P)_{M}=\text { measured concentration of cyclophosphamide }\left(\mathrm{pg} / \mathrm{cm}^{2}\right) \\
\text { and }(C P)_{T}=\text { theoretical concentration of cyclophosphamide }\left(\mathrm{pg} / \mathrm{cm}^{2}\right) \text {. } \\
+ \text { Relative cleaning effectiveness }(\mathrm{RCE} \text {, as } \%) \text { was calculated for each cleaning solution as } \\
\mathrm{RCE}=100-\left[\left(q_{(\mathrm{cs}+1)} / q_{(\mathrm{css}}\right) \times 100\right] \text {, where } q \text { is the measured quantity of cyclophosphamide } \\
\text { on the workbench }(\mathrm{pg}) \text { and } \mathrm{cs} \text { is the cleaning session }(1 \leq n \leq 5) \text {. }\end{array}$} \\
\hline
\end{tabular}

90\%, whereas for sessions 3 to 5, it was lower and more variable (from $61 \%$ to $92 \%$ for cleaning session 3 , from $28 \%$ to $78 \%$ for cleaning session 4 , and from $15 \%$ to $42 \%$ for cleaning session 5). From these data, we can formulate the general hypothesis that the smaller the residual quantity of cyclophosphamide, the less effective the cleaning products. Further studies are required to explore the factors associated with this hypothesis.

The effectiveness of a cleaning process can be influenced by 4 related factors in a modified Sinner circle: mechanical action, chemical action, time for action, and physicochemical properties of water. ${ }^{17}$ When one of these factors cannot be optimized, its lack is counterbalanced by an increase in the other factors. With regard to the mechanical action factor, the test procedure was realistic, given the usual time allowed per cleaning routine by hygiene and sanitation staff in hospitals; however, an improved cleaning procedure should require higher mechanical pressure from the operator to ensure better contact between the microfibres of the mop and the surface to be decontaminated. This approach could potentially increase decontamination efficacy, but this would need to be evaluated in further studies. The mechanism of chemical action of sodium hypochlorite and quaternary ammonium on cyclophosphamide is not completely known. This study suggests that both detergent and disinfectant are effective in decontaminating a surface exposed to cyclophosphamide, but it does not confirm the mechanisms of action of these cleaning products on the drug. Cyclophosphamide is a highly water-soluble drug, but its solubility in quaternary ammonium and sodium hypochlorite is unknown. It might be interesting to test the solubility and stability of cyclophosphamide in cleaning solutions in vitro to confirm the mechanism of action. With regard to the time for action, all of the cleaning solutions were prepared before the study began. Quaternary ammonium is stable over time, but sodium hypochlorite has a short half-life once diluted. Reducing the period between the preparation and use of sodium hypochlorite solutions might have enhanced the effects of the active ingredients. Finally, with regard to the physicochemical properties of water, it is unlikely that they decreased the efficacy of the cleaning products in our study. Cleaning solutions are prepared using water available in the study institution; water quality is assessed regularly, and hygiene staff check that cleaning products retain their properties once these solutions are prepared. Lukewarm water is always used, as recommended. ${ }^{17}$

A few additional factors may explain why the 3 solutions tested in this study did not completely eliminate surface contamination. For example, the disposable microfibre mops were used according to the institution's current cleaning procedure, which may have been unsatisfactory. The presence of an insufficient amount of cleaning solution in the microfibre may affect the 
mop's ability to solubilize and recuperate the cyclophosphamide on the surface. The current procedure allows retention of a maximum of $120 \mathrm{~mL}$ of cleaning solution in the mop once twisted. The amount of cleaning solution retained in the mop and the amount of cleaning solution in direct contact with the surface to be cleaned during the cleaning procedure are unknown. The net amount of cleaning solution may affect the decontamination rate. Moreover, current practice requires only one wash on the surface to be cleaned. An improved procedure would require additional washes, with additional soaking in the cleaning solution. Although current practice may be appropriate for general cleaning in some hospital areas (e.g., a wet-dry approach), it should be questioned for zones known to be contaminated with hazardous drugs. A greater amount of cleaning solution may be required to optimize current practice.

This study has confirmed the efficacy of sodium hypochlorite $0.02 \%$ and $2 \%$ and quaternary ammonium to clean a surface exposed to a substantial amount of cyclophosphamide, based on usual activities or small spills. However, sodium hypochlorite $2 \%$ appeared to be more effective than sodium hypochlorite $0.02 \%$ : the extent of cleaning with 2 sessions of the more concentrated solution was equivalent to that achieved with 5 sessions of the more dilute solution. Published surveillance studies have reported traces of hazardous drugs on various surfaces. ${ }^{18,19}$ Although these findings may be related to insufficient cleaning activities or improper techniques, they may also be related to the inefficacy of current cleaning strategies to completely remove traces of hazardous drugs. To address this problem, cleaning strategies should first be reviewed, but persistence of these traces may call for the use of more costly approaches (e.g., use of closedsystem transfer devices).

Additional studies are required to determine optimal cleaning strategies (e.g., types and amounts of agents to be used, number of cleaning sessions, contact times). In the meantime, hospitals should ensure more aggressive cleaning of surfaces potentially exposed to hazardous drugs, especially when traces of hazardous drugs are confirmed during periodic surveillance. Such cleaning should occur when no activities are in progress and no patients are present, to allow optimal cleaning. Standard 2014.02 of the Ordre des pharmaciens du Québec (for the compounding of hazardous sterile preparations), recommends that BSC workbenches be cleaned with a detergent or hydrogen peroxide, following by rinsing with water and disinfection with isopropyl alcohol $70 \%$, with this cleaning to be performed daily (at the beginning of the work day), after each change of preparation of hazardous drugs, and once a week (at the end of a working day). ${ }^{20}$ For more thorough disinfection, sodium hypochlorite $2.4 \%$ combined with sodium thiosulphate $1 \%$ is recommended for monthly application (at the end of a work day). Given the results reported here, we suggest weekly cleaning of the BSC workbench using sodium hypochlorite $2 \%$ or sodium hypochlorite $2.4 \%$ combined with sodium thiosulphate $1 \%$.
This study had some limitations. We studied only cyclophosphamide, which is a highly water-soluble drug. As reported in a prior study, the ability to remove cyclophosphamide does not reflect the ability to remove highly water-insoluble drugs (e.g., paclitaxel and docetaxel) or drugs with different binding characteristics (e.g., cisplatin). ${ }^{14}$ Thus, to thoroughly evaluate the effectiveness of a cleaning product to remove hazardous drugs, a wide variety of water-soluble and water-insoluble antineoplastic drugs must be tested. This study involved only 5 consecutive cleaning sessions. Although it would have been interesting to add further simulations with incremental tests to identify the maximal number of cleaning sessions required for complete removal of all traces of the drug, it is neither practical nor realistic to conduct multiple cleaning sessions on a regular basis. No traces of contaminant were detected after 5 additional cleanings, but incremental testing was not performed after these cleanings because of space and budget limitations. The sample size was too small to apply parametric statistical techniques for comparative analysis of the efficacy of the 3 cleaning products. A larger study, with more samples, would allow statistical comparison of the decontamination efficacy of the cleaning products. Because this was an exploratory study looking at the successive effectiveness of various cleaning products, we used numeric values below the limit of quantification but above the limit of detection to better illustrate the downward curve of efficacy. In contrast, environmental surveillance studies usually use the limit of quantification divided by 2 for values between that limit and the limit of detection. Here, we believe it was better to illustrate the relative decreasing effectiveness with trace amounts, nothwithstanding the uncertainty of these values.

\section{CONCLUSION}

All of the cleaning solutions tested were effective to decontaminate a workbench BSC intentionally contaminated with cyclophosphamide. Quaternary ammonium and sodium hypochlorite solutions $(0.02 \%$ and $2 \%)$ were equally effective in removing at least $95.241 \%$ of a $10^{7}$-pg quantity of cyclophosphamide after a single cleaning session. A smaller number of cleaning sessions was required with sodium hypochlorite $2 \%$. This study confirms that using sodium hypochlorite $2 \%$ for periodic decontamination of BSC is efficient. Further studies should be conducted to identify optimal cleaning strategies to fully eliminate traces of hazardous drugs. Finally, these results suggest a reduction in the efficacy of repeated cleaning sessions for residual traces of hazardous drugs.

\section{References}

1. Bussières JF, Sessink PJM, Prot-Labarthe S, Larocque D. Évaluation de l'exposition professionnelle aux antinéoplasiques dans une unité de pharmacie hospitalière. Arch Mal Prof Environ. 2006;67:(6):880-8. Article in French with English abstract.

2. Heinemann A, Eickmann U, Kiffmeyer TK, Tuerk J, Stuetzer H, Hahn M, et al. Wipe sample monitoring on workplace contamination with antineoplastic drugs in pharmacies. Hamburg (Germany): Berufsgenossenschaft für 
Gesundheitsdienst und Wohlfahrtspflege (BGW); 2008 [cited 2017 Nov 22]. Available from: https://www.bgw-online.de/DE/ArbeitssicherheitGesundheitsschutz/Grundlagen-Forschung/GPR-Medientypen/ Downloads/Poster-MEWIP-englischsprachig_Download.pdf?_blob= publicationFile

3. Turci R, Sottani C, Ronchi A, Minoia C. Biological monitoring of hospital personnel occupationally exposed to antineoplastic agents. Toxicol Lett. 2002;134(13):57-64.

4. Käslin E, Merz B, Rüegger M, Jost M. Contaminations de surface lors de la manipulation de médicaments cytostatiques dans les établissements de santé. Suva Med. 2010;:59-72. Article also available in German and Italian.

5. United States Pharmacopeia, Compounding Expert Committee and Compounding with Hazardous Drugs Expert Panel. USP general chapter $<800>$ hazardous drugs - handling in healthcare settings. Rockville (MD): United States Pharmacopeial Convention; 2017 [cited 2017 Apr 11]. Available from: http://www.usp.org/sites/default/files/usp/document/ our-work/healthcare-quality-safety/general-chapter-800.pdf

6. Decontamination and deactivation of antineoplastic agents. Atlanta (GA): Centers for Disease Control and Prevention, National Institute for Occupational Safety and Health; 2016.

7. Acampora A, Castiglia L, Miraglia N, Pieri M, Soave C, Liotti F, et al. A case study: surface contamination of cyclophosphamide due to working practices and cleaning procedures in two Italian hospitals. Ann Occup Hyg. 2005; 49(7):611-8.

8. Benvenuto JA, Connor TH, Monteith DK, Laidlaw JL, Adams SC, Matney TS, et al. Degradation and inactivation of antitumor drugs. J Pharm Sci. 1993;82(10):988-91.

9. Hon CY, Chua PPS, Danyluk Q, Astrakianakis G. Examining factors that influence the effectiveness of cleaning antineoplastic drugs from drug preparation surfaces: a pilot study. J Oncol Pharm Pract. 2014;20(3):210-6.

10. Queruau Lamerie T, Nussbaumer $S$, Décaudin B, Fleury-Souverain $S$, Goossens JF, Bonnabry P, et al. Evaluation of decontamination efficacy of cleaning solutions on stainless steel and glass surfaces contaminated by 10 antineoplastic agents. Ann Occup Hyg. 2013;57(4):456-69.

11. Touzin K, Bussières JF, Langlois É, Lefebvre M, Métra A. Pilot study comparing the efficacy of two cleaning techniques in reducing environmental contamination with cyclophosphamide. Ann Occup Hyg. 2010;54(3):351-9.

12. Anastasi M, Rudaz S, Queruau Lamerie T, Odou P, Bonnabry P, FleurySouverain S. Efficacy of two cleaning solutions for the decontamination of 10 antineoplastic agents in the biosafety cabinets of a hospital pharmacy. Ann Ocсир Hyg. 2015;59(7):895-908.

13. Lê LMM, Jolivot PA, Sadou Yaye H, Rieutord A, Bellanger A, Pradeau D, et al. Effectiveness of cleaning of workplace cytotoxic surface. Int Arch Occup Environ Health. 2013;86(3):333-41.

14. Cox J, Speed V, O'Neal S, Hasselwander T, Sherwood C, Eckel SF, et al. Development and evaluation of a novel product to remove surface contamination of hazardous drugs. J Oncol Pharm Pract. 2017;23(2):103-15.

15. Larson RR, Khazaeli MB, Dillon HK. Monitoring method for surface contamination caused by selected antineoplastic agents. Am J Health Syst Pharm. 2002;59(3):270-7.

16. Poupeau C, Tanguay C, Caron NJ, Bussières JF. Multicenter study of environmental contamination with cyclophosphamide, ifosfamide, and methotrexate in 48 Canadian hospitals. J Oncol Pharm Pract. 2016. doi:10.1177/1078155216676632. [Epub ahead of print].

17. Désinfectants et désinfection en hygiène et salubrité : principes fondamentaux. Québec (QC): Ministère de la Santé et des Services Sociaux du Québec; 2009 [cited 2017 Apr 11]. Available from: http://publications.msss.gouv.qc.ca/ msss/fichiers/2009/09-209-03F.pdf
18. Hazardous drug exposures in health care. Atlanta (GA): Centers for Disease Control and Prevention, National Institute for Occupational Safety and Health; 2014 [cited 2017 Nov 22]. Available from: https://www.cdc.gov/ niosh/topics/hazdrug/

19. Roland C, Caron N, Bussières JF. Multicenter study of environmental contamination with cyclophosphamide, ifosfamide, and methotrexate in 66 Canadian hospitals: a 2016 follow-up study. J Occup Environ Hyg. 2017;14(8):661-9.

20. Préparations de produits stériles dangereux en pharmacie : norme 2014.02. Montréal (QC): Ordre des pharmaciens du Québec; 2014 [cited 2017 Jun 19]. Available from: www.opq.org/doc/media/1847_38_fr-ca_0_norme_ 2014_02.pdf

Apolline Adé is with the Pharmacy Department and Pharmacy Practice Research Unit, CHU Sainte-Justine, Montréal, Quebec.

Laure Chauchat is with the Pharmacy Department and Pharmacy Practice Research Unit, CHU Sainte-Justine, Montréal, Quebec.

Johann-François Ouellette Frève, PharmD, MSc, is with the Pharmacy Department and Pharmacy Practice Research Unit, CHU Sainte-Justine, Montréal, Quebec

Sébastien Gagné is with the Centre de toxicologie du Québec, Institut national de santé publique du Québec, Québec, Quebec.

Nicolas Caron is with the Centre de toxicologie du Québec, Institut national de santé publique du Québec, Québec, Quebec.

Jean-François Bussières, BPharm, MSC, FCSHP, is with the Pharmacy Department and Pharmacy Practice Research Unit, CHU Sainte-Justine, and Faculty of Pharmacy, Université de Montréal, Montréal, Quebec.

Competing interests: None declared.

\section{Address correspondence to:}

Jean-François Bussières

Pharmacy Department

Centre hospitalier universitaire Sainte-Justine

3175, chemin de la Côte Sainte-Catherine

Montréal QC H3T 1C5

e-mail: jf.bussieres@ssss.gouv.qc.ca

Funding: None received.

Acknowledgements: The authors would like to thank Gabrielle Adam, of the Hygiene and Sanitation Department, CHU Sainte-Justine, for comments, training, and procurement of the materials. They would also like to thank pharmacy staff for compounding the cyclophosphamide into syringes and Cynthia Tanguay, Unité de recherche en pratique pharmaceutique, for manuscript review. 